J. Lake Sci.(湖泊科学), 2009, 21(5): 693-699

http://www.jlakes.org. E-mail: jlakes@niglas.ac.cn

(C2009 by Journal of Lake Sciences

\title{
南京市两个小型富营养湖泊浮游硅藻的季节性变化
}

\author{
姚 敏 ${ }^{1,2}$, 刘 倩 ${ }^{1,2}$, 李艳玲 ${ }^{1}$, 羊向东 ${ }^{* *}$ \\ (1: 中国科学院南京地理与湖泊研究所, 南京 210008) \\ (2: 中国科学院研究生院, 北京 100049)
}

摘 要: 为研究浅水富营养湖泊硅藻季节演替的规律, 选择南京两个城市湖泊(前湖和月牙湖)作为对象, 对水体硅藻和水质 进行逐月采样和实验分析. 结合数理统计分析手段, 对 2006 年硅藻浓度、种群组合变化及其与环境因子的关系进行了讨论. 结果表明: 两湖硅藻都呈现较明显的季节演替特点, 冬季浮游硅藻组合主要由 Cyclostephanos 的种类为主, 代表了冷水富营 养种组合类型; 夏季和秋季以 Cyclotella atomus 和 C. meneghiniana 暖水耐营养种优势组合为主. 硅藻和环境指标月富营养湖 泊，春季硅藻丰度增加对初级生产量的贡献很小; 随着营养程度的不断提高, 温度对浮游硅藻的限制更为突出. 关键词: 浮游硅藻; 季节变化; 水温; 营养因子; 典型对应分析(CCA)

\section{Seasonal change of planktonic diatom of two small shallow eutrophic lakes in Nanjing}

\author{
YAO Min ${ }^{1,2}$, LIU Qian ${ }^{1,2}$, LI Yanling ${ }^{1} \&$ YANG Xiangdong $^{1}$ \\ (1: Nanjing Institute of Geography and Limnology, Chinese Academy of Sciences, Nanjing 210008, P.R.China) \\ (2: Graduate School of the Chinese Academy of Sciences, Beijing 100049, P.R.China)
}

Abstract: For exploring the seasonal succession of planktonic diatom in shallow eutrophic lakes, two small shallow lakes-Lake Qianhu and Lake Yueya in Nanjing were chosen and monitored monthly in 2006. We discussed the relationship between the diatom density, diatom assemblages and environmental factors by the analyses of CCA. The results showed the obvious seasonal successions of diatom assemblages in the two lakes. Cyclostephanos was the dominant species in winter, representing the cool eutrophic diatom assemblage; while the assemblage changed into Cyclotella atoms and C. meneghiniana dominant in summer and autumn which represented warm and eutrophic assemblage. CCA analysis using the monthly data indicated that temperature did not only control the biomass of diatom, but also affected the seasonal succession of diatom assemblages. The increasing diatom biomass in spring had a little contribution to primary production. When the level of eutrophication was higher, the temperature plays more important role in influencing the planktonic diatom.

Keywords: Planktonic diatom; seasonal change; water temperature; nutrient factors; CCA

随着古湖沼学研究的深人, 现代生态学的信息愈来愈被重视, 并被广泛应用于古生态环境的解释中. 硅藻是食物链的重要初级生产者, 以其对环境变化敏感以及在沉积物中易于保存等特点, 已成为古湖沼 研究的一个重要生物指标 ${ }^{[1]}$. 近年来, 通过对现代湖泊硅藻的调查, 区域硅藻的空间分布特征及其与环 境要素的关系(如转换函数)已被很好地揭示 ${ }^{[2-3]}$. 然而, 这些研究大多基于湖泊表层沉积物大量数据的采 集, 尽管表层沉积物硅藻代表了一定水域不同生境的总体特征, 但其数据主要反映了一年甚至几年的总 体平均状况 ${ }^{[4]}$, 无法获得硅藻群落的年内变化信息, 由此也影响了硅藻古生态和古湖沼解释的精度 ${ }^{[5]}$. 事 实上，与其它浮游植物一样，硅藻丰度和群落存在季节性演替的规律. 通常认为，硅藻的年内生物量表

* 中国科学院知识创新工程重要方向项目(KZCX2-YW-319)和国家自然基金项目(40572177)联合资助. 2008-12-07 收稿; 2009-03-20 收修改稿. 姚敏, 女, 1983 年生, 博士研究生; E-mail: yao_2016@163.com.

** 通讯作者; E-mail: xdyang@niglas.ac.cn. 
现为春季最高, 秋季次之, 而夏季减少, 冬季最低 ${ }^{[6]}$, 但不同湖泊高生物量出现的时间存在差异 ${ }^{[7]}$, 而且种 群组合的季节演替受控于物理(气候和水文等)、化学和多生物因子相互作用的影响 ${ }^{[5]}$. 例如, Bradbury 通过 对美国 Minnesota 地区 Elk 湖的硅藻监测研究 ${ }^{[8]}$, 得出年内湖水结冰时间的长短和水文循环控制了硅藻种群 组成的变化. 同样, Hausmann \& Pienitz 通过对加拿大 Laurentian 地区 4 个湖泊多年的硅藻季节调查研究 ${ }^{[7]}$, 得出水温解释了硅藻群落季节变化的最大信息量, 但不同季节其它环境因子(结冰时间、水体混合和分层时 间、 $\mathrm{pH}$ 值、总磷和 $\mathrm{SiO}_{2}$ 浓度等)对硅藻的显著影响程度有明显差异. Köster \& Pienitz 通过沉积物捕获器对 美国 Bates 湖的硅藻进行了一年的监测 ${ }^{[5]}$, 发现硅藻的季节分布模式主要与湖水混合和分层有直接关系, 春 季和秋季水体混合时期以浮游和底栖种为主, 而夏季分层时期只有浮游种占绝对优势, 表明温度是导致硅 藻季节变化主要原因. 利用这些结果, 很好地解释了该湖过去 1000 年来的化石硅藻记录, 由此重建了古温 度的变化, 揭示了小冰期冬季水体混合时间明显增加、20世纪夏季分层逐渐加强的过程. 然而, 硅藻季节性 研究目前主要在北半球温带地区湖泊, 且以深水分层和低营养水体为代表, 这些研究较好地反映了自然影 响下硅藻季节演替的规律 ${ }^{[9-10]}$, 但对亚热带浅水富营养湖泊的硅藻季节变化规律研究关注极少.

在人类活动的强烈干扰下，长江中下游湖泊尤其是城市湖泊的富营养化问题已非常严重，已有的近 50 个湖泊表层沉积硅藻研究显示, 由于表层沉积物一年甚至几年的平均状况, 因此这些表层沉积硅藻与 水质的年平均值对应 ${ }^{[1-12]}$. 然而, 季节尺度上富营养湖泊硅藻群落与环境的关系目前尚不清楚. 为此, 本研究选择了南京市两个城市湖泊(前湖和月牙湖)作为对象, 通过硅藻逐月的监测, 获得富营养湖泊硅 藻季节演替规律, 理解硅藻群落变化对环境因子的响应关系, 为古生态环境的解释提供更高时间分辨率 的硅藻生态变化的信息, 同时为现代生态学的研究提供基本数据.

\section{1 研究地点}

选择的两个城市湖泊均位于南京市东郊(图 1). 前湖位于钟山风景区内, 面积 $0.1 \mathrm{~km}^{2}$, 平均水深约 $2 \mathrm{~m}$. 根 据 2006 年水质月监测结果(本文), 该湖水质目前已处于富营养状态, 湖水总氮(TN)、总磷(TP)浓度月平均值分 别为 $1.69 \mathrm{mg} / \mathrm{L}$ 和 $0.1 \mathrm{mg} / \mathrm{L}, \mathrm{pH}$ 值在 7.5-8.5 之间. 湖泊环境主要受景区旅游业的影响. 月牙湖位于东郊风景区 内, 原是护城河的一段, 面积 $0.17 \mathrm{~km}^{2}$, 平均水深约 $2 \mathrm{~m}$. 由于沿岸生活污水的排放, 加之旅游业的影响, 该湖 水体富营养程度较前湖严重, 2006 年湖水月平均 TN 浓度达 $2.78 \mathrm{mg} / \mathrm{L}, \mathrm{TP}$ 浓度 $0.26 \mathrm{mg} / \mathrm{L}, \mathrm{pH}$ 在 7-9 之间.

\section{2 材料和方法}

两个湖泊的监测样点均位于湖中心部位(图 1), 现场测量水深、透明度(SD)、 $\mathrm{pH}$ 值、电导率和表层

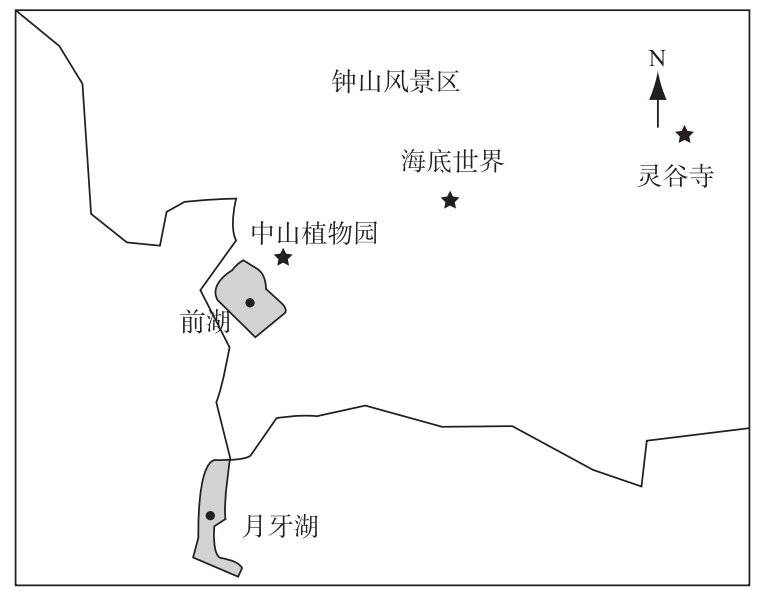

图 1 前湖和月牙湖地理位置和采样点分布

Fig.1 Location and sampling sites of Lake Qianhu and Lake Yueya 水温度 $(\mathrm{T})$. 采集水下 $50 \mathrm{~cm}$ 处的水样带回实验 室进行水化学分析, 测试项目包括 TP、TN、叶 绿素 a(Chl.a)、化学耗氧量 $(C O D)$. TN、TP 和 Chl.a 浓度用 752 型分光光度计测定，其中 TN 采用碱性过硫酸钾消解紫外分光光度法, TP 采 用钿酸铵分光光度法测定，叶绿素 a 用丙酮萃 取法提取, $\mathrm{COD}$ 测定是用高锰酸钾 $\left(\mathrm{KMnO}_{4}\right)$ 指 数法. 样品分析方法参照《地表水环境质量标 准》和《湖泊富营养化调查规范》进行 ${ }^{[13]}$.

对硅藻样品, 在采样点取 $1000 \mathrm{ml}$ 水样, 其 中 $500 \mathrm{ml}$ 立即用鲁格试剂固定, 实验室将其倒 人量筒中沉淀 $48 \mathrm{~h}$, 用吸管将上层清液吸出, 下层浓缩液倒入烧杯中加热至 $150^{\circ} \mathrm{C}$, 加少量 浓 $\mathrm{HCl}$ 去处碳酸盐, 稍后加 $30 \%$ 的 $\mathrm{H}_{2} \mathrm{O}_{2}$ 去除 有机质, 待反应结束后, 加满蒸馏水清洗 3 次 并离心, 提取硅藻浓缩液, 最后在浓缩液中加 
人已知数量的指示性小球用于硅藻浓度计算. 硅藻制片后在 Leica生物显微镜下进行鉴定和计数, 硅藻鉴 定根据 Krammer 和 Lange-Bertalot 的分类系统 ${ }^{[13]}$. 每个样品统计至少 500 粒，属种丰度用百分比和总浓 度表示. 其中浓度计算公式为:

$$
C=P_{1} V_{1} N_{2} / N_{1} V_{\text {水 }}
$$

其中, $P_{1}$ 为小球浓度, $V_{1}$ 为加人的小球体积, $N_{2}$ 为硅藻计数个数, $N_{1}$ 为小球计数个数, $V$ 水为水样体积.

考虑到水体硅藻对水环境的响应可能存在一定的滞后，所有水质指标用当月和前一个月的平均值表 示. 对硅藻数据, 选择至少在 2 个月份中出现且至少在一个月份中含量大于 $1 \%$ 的属种, 对其含量进行平 方根转换. 由于缺少前湖 10 月, 月牙湖 8 月和 10 月的硅藻数据, 故在数值分析时将相应的水质数据删除. 利用典型对应分析(CCA)进行硅藻与环境因子的关系揭示.

\section{3 研究结果}

\section{1 环境因子的季节变化}

前湖总磷 $(\mathrm{TP})$ 浓度 2006 年月平均值为 $0.1 \mathrm{mg} / \mathrm{L}$ 左右, 其中冬季最高 $(0.18-0.2 \mathrm{mg} / \mathrm{L})$, 春季下降, 夏季 最低 $(0.03-0.07 \mathrm{mg} / \mathrm{L})$, 而秋季有所增加. TN 浓度的变化趋势与 TP 比较一致, 但 TN 浓度在 $7 、 8$ 月则有 所回升; Chl.a 浓度自 5 月开始明显增加, 5-7 月在年内呈峰值段 $(50-90 \mu \mathrm{g} / \mathrm{L}) ; \mathrm{COD}$ 浓度的快速增高出现在 4 月, 略早于 Chl.a 浓度的增加, 其峰值也一直维持到 7 月; $\mathrm{pH}$ 值变化不大，总体上在 1-7 月较高, 6 月出 现小峰值(8.0)，8-12 月偏低; 电导率变化比较复杂，规律性不明显. 前湖水温变化冬季最低，自春季开始 逐渐增高, 夏季和秋季出现峰值段 $\left(20-25^{\circ} \mathrm{C}\right)$, 尤以秋季最高(图 2a).
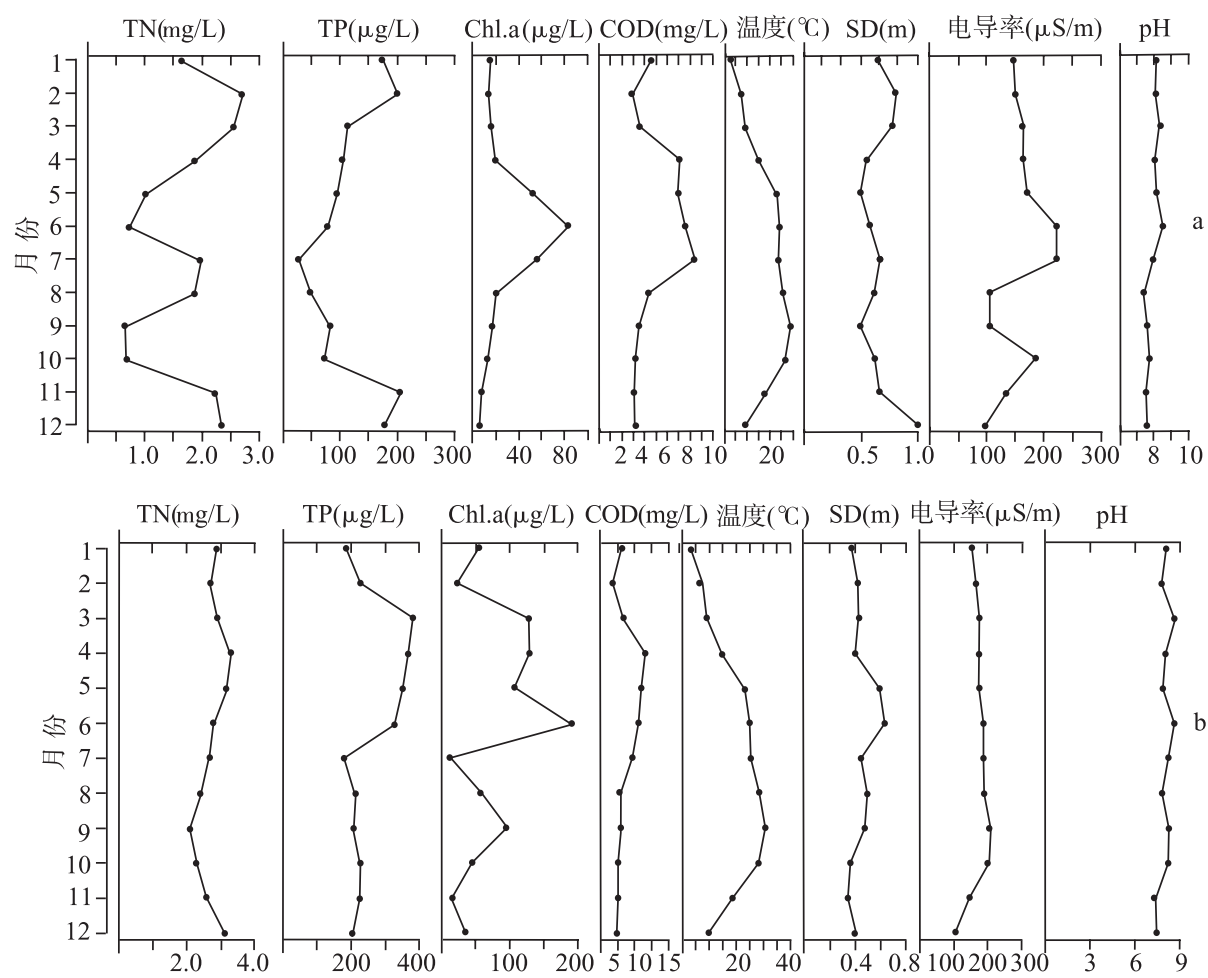

图 22006 年前湖(a)、月牙湖(b)环境指标月变化

Fig.2 Changes of environmental factors of Lake Qianhu(a) and Lake Yueya(b) in 2006

月牙湖水质的富营养程度明显高于前湖, 其 TP 浓度的 2006 年月均值 $(0.26 \mathrm{mg} / \mathrm{L})$ 达到前湖的 2.6 倍. 测定的环境因子中，除水温和 COD 浓度变化趋势比较一致外，其余指标变化差别较大. TP 冬季、秋季相 
对偏低 $(0.2-0.25 \mathrm{mg} / \mathrm{L})$, 春季和夏季最高 $(3.5-3.9 \mathrm{mg} / \mathrm{L})$, 但 7 月下降; $\mathrm{TN}$ 浓度在冬、春季偏高, 秋季最低; Chl.a 浓度冬季最低，春、夏、秋季高 $(100-140 \mu \mathrm{g} / \mathrm{L})$, 但 7 月出现一次快速的下降; $\mathrm{pH}$ 值在春季到秋季偏 高, 但有波动; 透明度全年都较低, 但在春末 5-6 月份有个小的峰值, 电导率从冬季到秋季总体呈微弱增 高趋势(图 2b).

\section{2 浮游硅藻季节变化}

前湖共鉴定硅藻 21 属 52 种, 但优势种不多, 主要是 Cyclotella pseudostelligera、C. atoms、C. meneghiniana、Cyclostephanos dubius、Synedra nana，另有一定含量的 Cyclostephanos invistatus、C. tholiformis、Stephanodiscus hantzschii、Aulacoseira alpigae、Aulacoseira granulata 和 Nitzschia palea 等种 (图 3a). 从组合分布情况来看, 硅藻呈现良好的季节性演替, 其中 1-3 月份以 Cycostephanos dubius、C. invistatus、C. tholiformis、Stephanodiscus hantzschii 等为组合特征; 4 月份为 Cyclotella pseudostelligera 单 优势种组合；5-9 月份 Cyclotella pseudostelligera 明显减少，以 Cyclotella atomus、C. meneghiniana 和 Nitzschia palea 为主, 且伴随其他种类较多; 11 月份出现多优势组合特征，但 12 月份 Synedra nana 成为单 优势种组合. 硅藻浓度的峰值出现在 4-8 月, 最高达 $1700 \mathrm{ind} . / \mathrm{ml}$, 其它月份的浓度值都低于 400ind./ml(图 3a). 浓度的变化与硅藻组合没有明显的对应关系.

月牙湖硅藻共检出 21 属 46 种，种类组成与前湖基本一致(图 3b), 构成季节硅藻组合的主要优势种 与前湖相比，变化不大，但伴生种的出现在季节上存在一定差别，尤其是伴浮游种类. 1-3 月份仍以 Cycostephanos 的种类占优势，但 Stephanodiscus hantzschii 很少, Nitzschia palea 含量却很高，而后者在 前湖主要出现在夏季. Cyclotella pseudostelligera 在该湖 4 月份占绝对优势, 12 月份再次出现丰值. 5-9 月份 Cyclotella atomus、C. meneghiniana 在两个湖中均以优势种出现，但后者在全年含量均较高. 此外, 该湖硅藻浓度峰值出现在 11-12 月间(500-1200ind./ml)，而 4-6月间的硅藻浓度仅略微增高，与前湖有 明显差别(图 3).

\subsection{CCA 分析结果}

典型对应分析(CCA)是通过属种与环境指标数据的分析，并将环境指标作为矢量，在双轴图中(第一 和第二指标轴)直观地反映出硅藻、月采样点与各环境指标的关系. CCA 分析结果表明, 前两个轴的特征 值 $(\delta 1=0.301, \delta 2=0.126)$ 解释了 $63 \%$ 的硅藻信息量. 图 4 中环境因子的排列显示, SD 和 Chl.a、TP、TN 等 呈明显的反相关关系, 代表了营养梯度的主要方向; 水温指标与各营养指标相关性较弱, 解释的硅藻信 息量较其它营养指标要高, 代表了一个独立的环境梯度. 根据主要硅藻种的分布，夏季和秋季优势种 Cyclotella atomos、C. meneghiniana 位于水温梯度的正方向, C. pseudostelligara 作为春季的绝对优势种, 位 于近原点附近，而冬季出现的Cyclostephanos dubius、C. tholiformis、C. invistatus、Stephanodiscus hantzschia 等则位于水温梯度的负方向. 硅藻种的分布在营养梯度的方向上无明显的规律性特点, 但两个湖月采样 点的分布在营养梯度上被明显区分出来，营养程度相对低的前湖位于营养梯度的负方向，而 TN 和 TP 较 高的月牙湖月采样点均位于正方向. 进一步的分析(Forward selection)和蒙特卡罗检验表明，当所有环境 指标用于两个湖的硅藻数据分析时, 温度和透明度都是显著的环境变量 $(P<0.05)$, 但当这些环境指标分 别用于各个湖的硅藻分析时(图未显示), 前湖中 $\mathrm{T} 、 \mathrm{TP}$ 和 SD 也通过了检验，而月牙湖中，水温仍是唯一 显著的环境指标.

\section{4 讨论与结论}

分析结果表明, 无论是前湖还是月牙湖, 硅藻的分布都呈现较明显的季节分布特点. 晚冬和早春 (1-3 月份)浮游硅藻主要由 Cyclostephanos 的种类为主, 代表了冷水组合类型; 夏季和秋季为 C. atomus 和 C. meneghiniana 暖水种优势组合, 早冬(11-12 月份)两个湖泊硅藻变化比较复杂. 一些伴生种, 如 Aulacoseira alpigae、Nizschia palea 等, 在两个湖泊的不同月份出现, 很可能与采样点周围的微生境条 件有关. 然而, 除 Cyclotella pseudostelligara 和少量半浮游种外, 大多数硅藻均为耐富营养种. 在长江中 下游硅藻数据库中, 这些浮游种类均有很高的总磷适宜值, 在欧洲一些富营养浅水湖泊中也很常见 ${ }^{[14]}$, 并被作为富营养水体的主要指示种 ${ }^{[15]}$. 


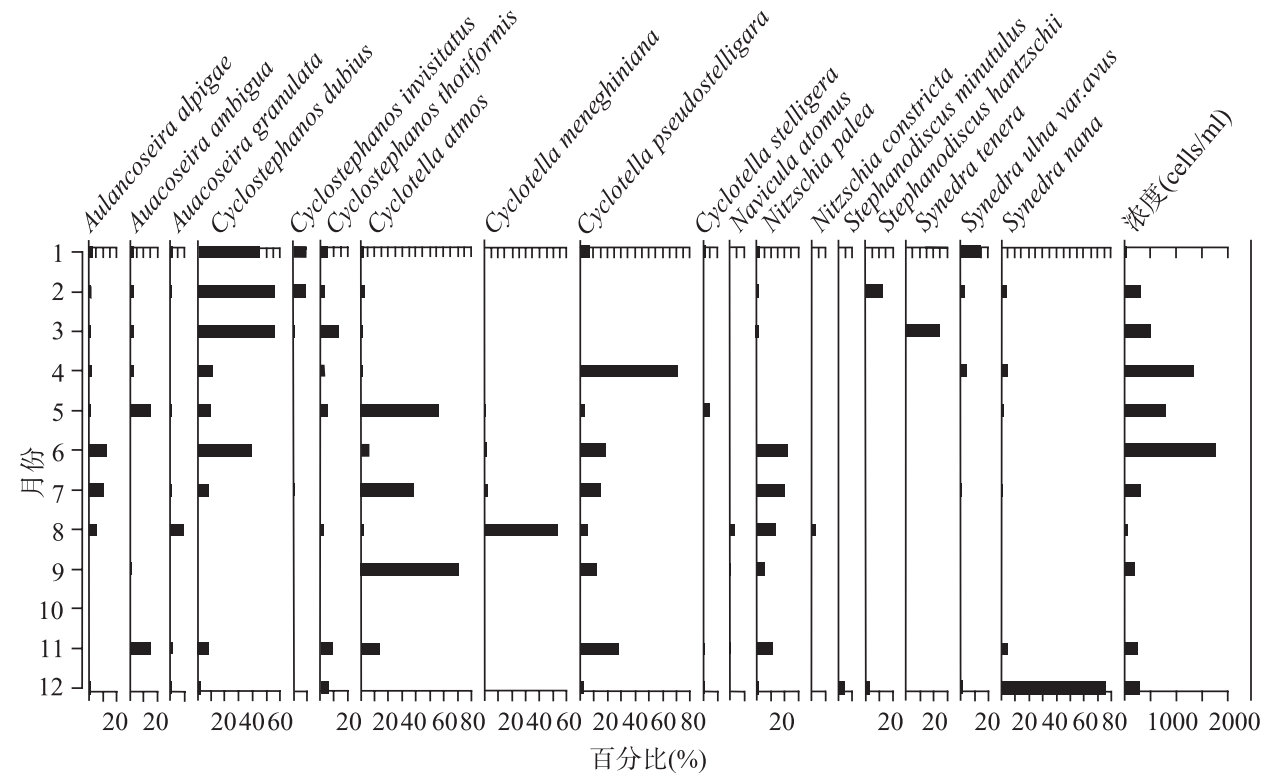

(a)

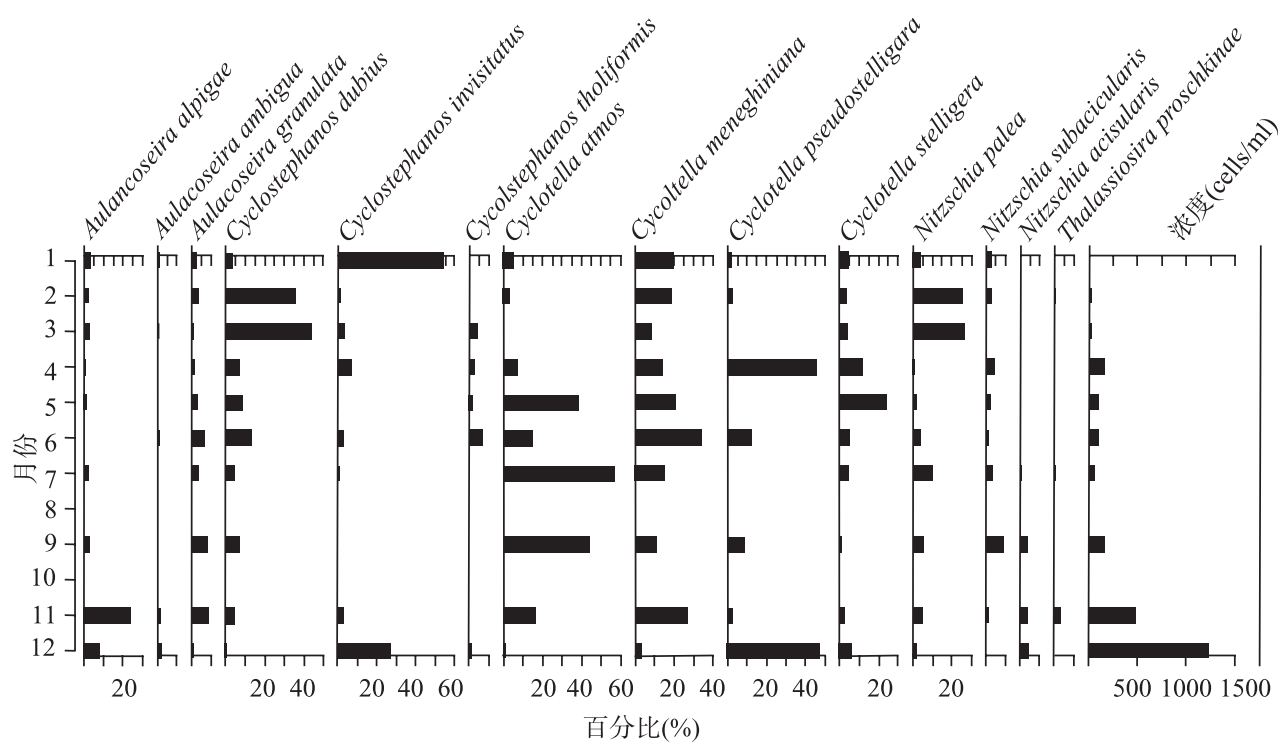

(b)

图 32006 年前湖(a)、月牙湖(b)硅藻组合和总浓度变化

Fig.3 Diatom assemblages and total concentrations of Lake Qianhu(a) and Lake Yueya(b) in 2006

温度是浮游植物季节变化的主要非生物因子 ${ }^{[16]}$. 前湖和月牙湖硅藻浓度的峰值出现均以 $C$. pseudostelligera 的突然增加为主, 且水温变化范围在 $10-15^{\circ} \mathrm{C}$ 之间, 但两个湖泊硅藻浓度的峰值分别在不 同的季节(春季和冬季), 这种差异反映在富营养湖泊，和湖泊的营养程度即 $\mathrm{N} 、 \mathrm{P}$ 的含量有关，而且浮游 植物的种间竞争 ${ }^{[17]}$ 有关. 前湖春季硅藻浓度达到最大符合硅藻的生长规律 ${ }^{[18]}$, 但秋季硅藻浓度偏低, 原 因可能与水体营养盐浓度下降有关，夏季降水较多，对营养盐一定的稀释作用，所以秋季营养盐尤其是 $\mathrm{TP}$ 浓度明显下降. 月牙湖春季硅藻浓度出现一个小峰值, 但最大丰度出现在早冬月份. 根据 Chl.a 浓度的 
变化，推测该湖春季硅藻丰度偏低可能受其他藻类竞争胁迫有关，而 11-12 月份丰度的明显上升一方面 与水温开始下降，而其它藻类(特别是蓝藻)竞争压力降低有关.

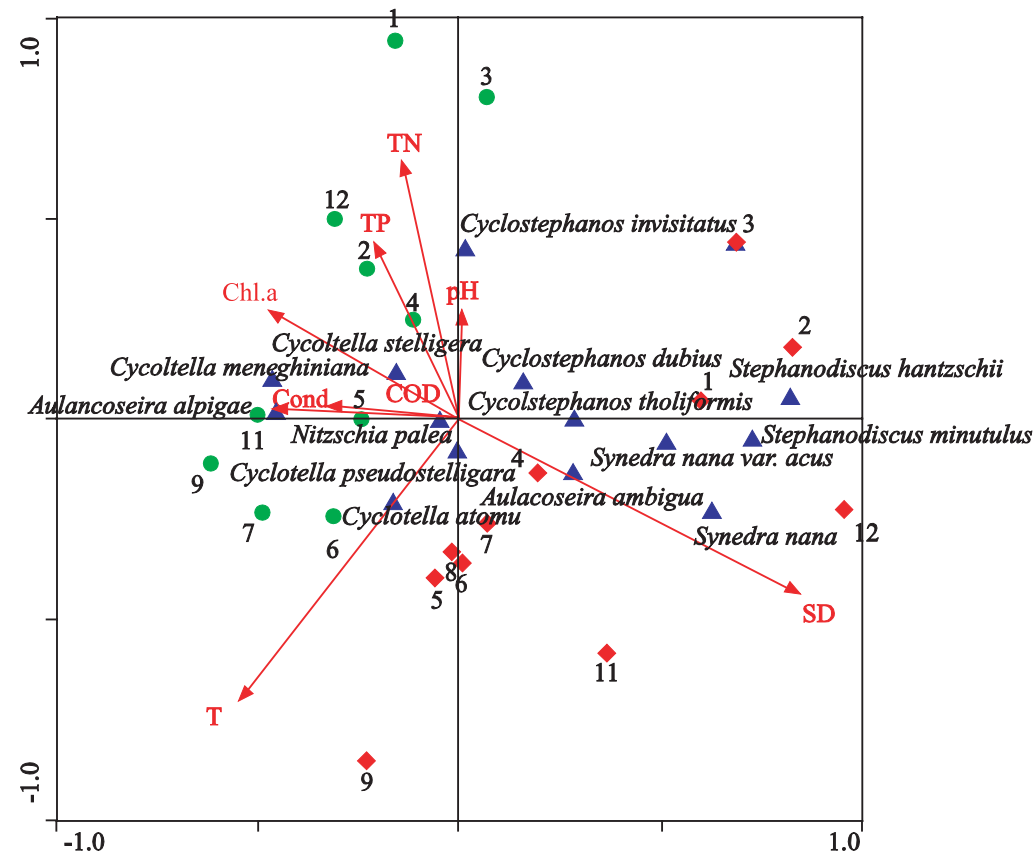

图 4 前湖和月牙湖硅藻与环境数据的 $\mathrm{CCA}$ 分析结果

Fig.4 The result of the CCA using diatom taxa and environmental variables in Lake Qianhu and Lake Yueya

前湖和月牙湖硅藻和环境指标月监测数据的 CCA 分析结果进一步揭示出温度是影响这两个湖泊浮 游硅藻群落季节变化重要和显著的环境因子, 很好地区分了冬季和夏秋季的硅藻组合. 由此说明温度不 仅控制了硅藻产量的变化，而且也影响了硅藻种群组合的季节分布和变化.

图 4 表示透明度与硅藻存在显著关系, 然而当月牙湖数据单独进行 CCA 分析时 SD 与硅藻的关系并 不显著, 因此 SD 对硅藻的显著影响体现在前湖中. 图 2a 中透明度下降与 Chl.a 并没有呈现反向关系, 但 在图 4 中相对 Chl.a 反向, 因此 SD 对硅藻的影响是与 Chl.a 共同作用的结果.

前湖春季 Chl.a 浓度的升高较硅藻浓度的峰值提前, 其低值的出现也晚于硅藻峰度的降低(图 2a, 图 $3 a)$. 月牙湖 Chl.a 浓度在整个春季至秋季大多维持在很高的水平 $(100-140 \mu \mathrm{g} / \mathrm{L}), 7$ 月份其浓度的下降在太 湖也有报导 ${ }^{[19]}$, 并被认为是与降水有关的人湖径流增多有关. 但月牙湖硅藻浓度在整个 Chl.a 高值段均 很低, 说明在这两个富营养湖泊, 硅藻在浮游藻类群落中不占主要地位, 春秋季硅藻丰度增加对初级生 产量的贡献很小.

温度与硅藻季节分布的关系目前已被欧洲和北美温带湖泊的研究所证实，但这些被监测的温带湖 泊营养程度通常较低，本研究中CCA分析揭示出除温度及与温度相关的物理指标外，湖水 TP等一些营 养指标对硅藻数据也有一定的显著解释能力, 反映在季节尺度上水体营养梯度的存在, 并影响着硅藻 的季节演替. 前面提到, 当单独对前湖硅藻和环境指标数据进行CCA分析时, TP对硅藻数据仍有显著 的解释能力; 但当单独对月牙湖数据进行分析时, 只有温度的解释是显著的, 这可能表明, 随着营养 程度的不断提高, TP已不再成为富营养湖泊硅藻变化的主要影响因素, 而温度的限制则变得更为突出. 长江中下游 49 个湖泊的硅藻与 TP浓度的转换函数研究结果也表明 ${ }^{[12,15]}$, 随着富营养程度的增加, 硅藻 逐渐过渡为以 C. atomus和C. meneghiniana为优势的组合, 其对TP的耐受范围也明显加大, 这与本研究 的结论尤为相似. 
致谢: 王荣博士、姚远博士、董旭辉博士协助了部分野外采样工作, 潘洪焦高级工程师指导了水化学的 实验分析, 在此一并表示感谢.

\section{5 参考文献}

[1] Dong XH, Bennion H, Battarbee R et al. Tracking eutrophication in Taihu Lake using the diatom record: potential and problems. Journal of Paleolimnology, 2008, 40: 413-429.

[2] Werner P, Smol JP. Diatom-environmental relationships and nutrient transfer functions from contrasting shallow and deep limestone lakes in Ontario, Canada. Hydrobiologia, 2005, 533: 145-173.

[3] Lim DSS, Smol JP, Douglas MSV. Diatom assemblages and their relationships to lakewater nitrogen levels and other limnological variables from 36 lakes and ponds on Banks Island, N.W.T., Canadia Arctic. Hydrobiologia, 2007, 586: 191-211.

[4] Anderson NJ. Variability of diatom-inferred phosphorus profiles in a small lake basin and its implications for histories of lake eutrophication. Journal of Paleolimnology, 1998, 20: 47-55.

[5] Koster D, Pienitz R. Seasonal diatom variability and paleolimnological inferences-a case study. Journal of Paleolimnology, 2006, 35: 395-416.

[6] Arhonditsis G, Brett MT, Frodge J. Environmental control and limnological impacts of a large recurrent spring bloom in Lake Washington, USA. Environmental Management, 2003, 31: 604-618.

[7] Hausmann S, Pienitz R. Seasonal climate inferences from high - resolution modern diatom data along a climate gradient: a case study. Journal of Paleolimnology, 2007, 38: 73-96.

[8] Bradbury JP. A climate-limnologic model of diatom succession for paleolimnological interpretation of varved sediments at Elk Lake, Minnesota. Journal of Paleolimnology, 1988, 1: 115-131.

[9] Lim DSS, Douglas MSV, Smol JP. Diatoms and their relationship to environmental variables from lakes and ponds on Bathurst Island, Nunavut, Canadian High Arctic. Hydrobiologia, 2001, 450: 215-230.

[10] Cetinic C, Vilicic D, Buric Z. Phytoplankton seasonality in a highly stratified karstic estuary(Krka, Adriatic Sea). Hydrobiologia, 2006, 555: 31-40.

[11] 董旭辉，羊向东, 潘红坌. 长江中下游地区湖泊现代沉积硅藻分布基本特征. 湖泊科学, 2004, 16(4): 298-304.

[12] Yang XD, Anderson NJ, DONG XH et al. Surface sediment diatom assemblages and epilimnetic total phosphorus in large, shallow lakes of the Yangtze floodplain: their relationships and implications for assessing long-term eutrophication. Freshwater Biology, 2008, 53: 1273-1290.

[13] 金相灿, 屠清瑛. 湖泊富营养化调查规范. 北京: 中国环境科学出版社, 1990

[14] Bennion H. A diatom-phosphorus transfer function for shallow, eutrophic ponds in southeast England. Hydrobiologia, 1994, 275/276: $391-410$

[15] 董旭辉，羊向东，王 荣. 长江中下游地区湖泊富营养化的硅藻指示性属种. 中国环境科学, 2006, 26(5): 570-574.

[16] 赵孟绪, 雷腊梅, 韩博平. 亚热带水库浮游植物群落季节变化及其影响因素分析一一以汤溪水库为例. 热带亚热带植物 学报, 2005, 13(5): 386-392.

[17] 朱 伟, 万 蕾, 赵联芳. 不同温度和营养盐质量浓度条件下藻类的种间竞争规律. 生态环境, 2008, 17(1): 6-11.

[18] 章宗涉, 黄翔飞主编. 淡水浮游生物研究方法. 北京: 科学出版社, 1991: 12.

[19] 蔡启铭, 高锡芸. 太湖梅梁湾口浮游植物初级生产力及其相关因素关系的研究. 湖泊科学, 1994, 6(4): 340-347. 